\title{
A retrospective analysis of surgical approach to the mediastinal lesions
}

\author{
Ersin Sapmaz ${ }^{1}$, Merve Şengül İnan ${ }^{1}$, Hakan Işık ${ }^{1}$, Okan Karataş ${ }^{2}$, Kuthan Kavaklı ${ }^{1}$, Onur Genç ${ }^{1}$ \\ (1) University of Health Sciences, Gulhane Training and Research Hospital, Department of Thoracic Surgery, Ankara, \\ Turkey \\ (2) Sinop Atatürk State Hospital, Department of Thoracic Surgery, Sinop, Turkey
}

\author{
Date submitted: \\ Jun 08, 2019 \\ Date accepted: \\ Jul 07, 2019 \\ Online publication date: \\ September 15, 2019

\section{Corresponding Author: \\ Ersin Sapmaz \\ University of Health Sciences, \\ Gulhane Training and Research \\ Hospital, Department of \\ Thoracic Surgery, Ankara, \\ Turkey \\ dr.esapmaz@gmail.com}

Keywords: Robotic surgery, mediastinal tumor, sternotomy, thoracotomy, VATS, RATS.

\begin{abstract}
Aims:The mediastinal masses represent a wide variety of diseases. Most of the masses are detected incidentally. The patient's symptoms usually occur as a result of compression or invasion of the surrounding tissue. In spite of difficult anatomic access for tumors of mediastinum, surgical resection remains the best diagnostic and therapeutic approach. In this study, we aimed to show the surgical modalities according to the mediastinal location and the changes in the surgical methods applied to the lesions with similar pathologies in time.

Methods:We retrospectively reviewed the medical records of patients between 2003 and 2018 who underwent surgical intervention for mediastinal masses. A total of 241 patients included to the study. The age, sex, surgical methods, pathology results, localization of the masses, pathology results, surgical methods according to the localizations and changing of surgical methods applied to patients with the same regions and the same pathologies were examined in time.

Results:Of the 241 patients, 69 (28.6\%) were female and 172 (71.4\%) were male. The lesions were located in the anterior mediastinum in $164(68.1 \%)$ patients, in the middle mediastinum in $40(16.6 \%)$ and in the posterior mediastinum in $37(15.3 \%)$ of the patients. In the last 5 years, $69(67 \%)$ of 103 patients had robotic surgery and $10(9.7 \%)$ had sternotomy.

Conclusions:Preoperative evaluation of mediastinal lesions should be performed carefully. The advantages of minimally invasive procedures should always be considered for selected patients. Minimally invasive procedures can be used safely in the complete resection of selected mediastinal masses.
\end{abstract}

\section{Introduction}

The masses of the mediastinum represent a wide variety of diseases, from thymic hyperplasia to thymic carcinoma, other primary tumors to metastatic disease. Most of the mediastinal masses are detected incidentally during scanning tests for other reasons. The patient's symptoms usually occur as a result of compression or invasion of the surrounding tissue, not the disease itself.

Mediastinal masses are localized by dividing the mediastinum into 3 areas based on the anatomical structures: the anterior mediastinum, the middle mediastinum, and the posterior mediastinum. Superior mediastinum is also defined according to radiological images (1). Although more than two thirds of mediastinal masses are benign, predilection for malignancy is higher in the anterior compartment $(60 \%$ of all mediastinal malignancies) (2).

Although median sternotomy is the traditional surgical method for mediastinal masses, it shows a tendency toward video-assisted thoracoscopic surgery (VATS) and robot-assisted thoracoscopic surgery (RATS) in patients with appropriate in- dications $(3,4)$. In spite of difficult anatomic access for tumors of mediastinum, surgical resection remains the best diagnostic and therapeutic approach. The choice of surgical technique depends on the location of the lesion, other associated clinical factors such as body habitus, previous surgery, extent of disease, and the availability of special techniques and equipment (5).

In this study, we aimed to show the surgical modalities applied to the masses according to the mediastinal location of the hospitalized patients in our clinic and the changes in the surgical methods applied to the lesions with similar pathologies in time.

\section{Methods}

In our Institution's thoracic surgery department, we retrospectively reviewed the medical records of patients between 2003 and 2018 who underwent surgical intervention or resection because of mediastinal masses. Patients who were not operated in our clinic or operated in other centers, patients with mediastinal masses who had non-mediastinal lymph node biopsy (e.g. scalene lymph node sampling) and patients who had no 
Table-1: Surgical procedures according to mediastinal location of lesions

\begin{tabular}{lcccc} 
& Anterior Mediastinum & Middle Mediastinum & Posterior Mediastinum & Total \\
\hline Thoracotomy & 14 & 29 & 25 & 68 \\
\hline Sternotomy & 63 & 2 & - & 65 \\
\hline Anterior Mediastinotomy & 17 & - & 6 & 17 \\
\hline VATS & 11 & 5 & 6 & 22 \\
\hline RATS & 59 & 4 & 37 & 69 \\
\hline Total & 164 & 40 & & 241 \\
\hline
\end{tabular}

mediastinal mass and who underwent surgery for lymph node sampling only (e.g. mediastinoscopy) were excluded from the study. A total of 241 patients who were selected according to the above criteria were included in the study. Antero-posterior / lateral chest $\mathrm{x}$-ray, thorax tomography, positron emission tomography, scintigraphy and magnetic resonance imaging were used to detect the lesions. The age, sex, surgical methods, pathology reports, localization of the masses, pathology reports according to the localizations, surgical methods according to the localizations and changing of surgical methods applied to patients with the same regions and the same pathologies were examined in time. Approval for the study was granted by the Ethics Committee of Gulhane Training and Research Hospital (Approval Date: March 12, 2019, Approval Number: 19/11).

\section{Results}

In our study, 69 (28.6\%) of the 241 patients operated for mediastinal lesion were female and $172(71.4 \%)$ were male. The mean age was 35.8 years. The lesions were located in the anterior mediastinum in $164(68.1 \%)$ patients, in the middle mediastinum in 40 (16.6\%) and in the posterior mediastinum in 37 $(15.3 \%)$ of the patients.

It was observed that $69(28.6 \%)$ patients had robotic surgery, $68(28.2 \%)$ patients had posterolateral or muscle sparing thoracotomy, 65 (27\%) had median or partial sternotomy, $22(9.1 \%)$ had VATS and $17(7.1 \%)$ had anterior mediastinotomy. Surgical procedures of mediastinal cysts and masses according to mediastinal locations are shown in Table 1. The mean hospital stay was 5.5 days.

When the distribution of surgical procedures in the 16-year period covered by the study is analyzed, it is noteworthy that robotic surgery, which has been in practice since 2014, constitutes the majority of cases. One hundred and three patients underwent surgery in the last 5 years and in comparison, 69 $(67 \%)$ of the patients had robotic surgery and $10(9.7 \%)$ of the patients had sternotomy. When the approach to mediastinal cysts and masses has been examined since 2010, the procedures performed with traditional thoracotomy and sternotomy have been decreased and the approaches with video thoracoscopic and robotic surgery have increased (Table 2).

\section{Anterior Mediastinal Mass Group}

Of the $164(68 \%)$ patients who underwent surgery for anterior mediastinal mass or cyst, $113(68.9 \%)$ were male and 51 $(31.1 \%)$ were female. The mean age of the patients was 37.9 years. Forty-four $(26.8 \%)$ of the patients had no complaints. In this group, 32 patients with Myasthenia Gravis (MG) were present, and the patients with MG reported myasthenic complaints such as diplopia, weakness and dysphagia. Regardless of MG, the most common complaint was chest pain (15.2\%) and dys-
Table-2: Distribution and change of minimally invasive surgical procedures in the 16-year period

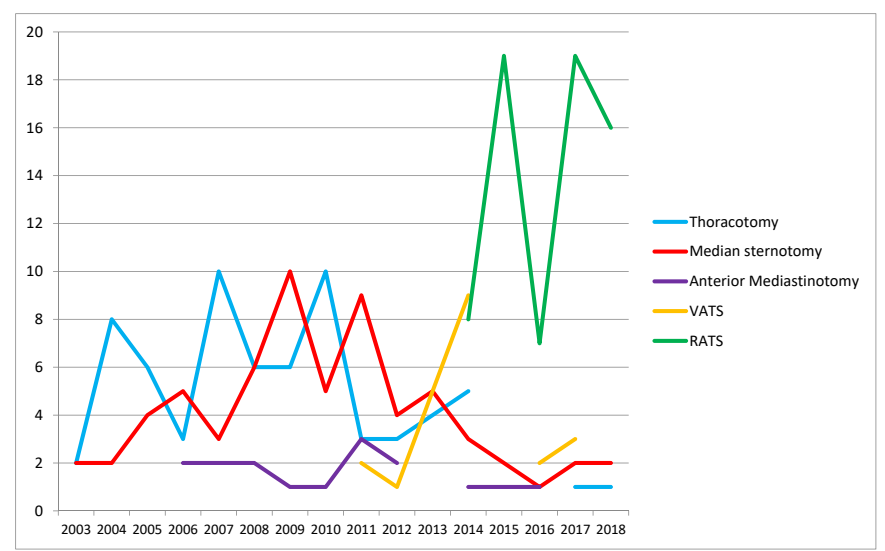

pnea $(7.3 \%)$. The mean length of hospital stay was 5.1 days in this group. In the preoperative evaluation of the lesions in the anterior mediastinum, 162 (98.8\%) patients had thorax CT. Four patients underwent both by CT scan and PET-CT scan, while one patient underwent only a PET-CT scan. In addition, CT and parathyroid scintigraphy were performed in 5 patients, CT and thyroid scintigraphy were performed in 1 patient and MRI was performed only in 1 patient according to the structure of the lesions. In this patient group, 35 (21.3\%) patients underwent CT-guided transthoracic needle biopsy for preoperative diagnosis. In 15 patients, the procedure was not diagnostic but 20 patients were diagnosed. A total of 129 (78.7\%) patients underwent operation without preoperative diagnosis. Median sternotomy was performed in 63 , robotic surgery in 59 , anterior mediastinotomy in 17, thoracotomy in 14, and VATS in 11 of the mediastinal masses or cysts located in the anterior mediastinum. Of the 164 patients in the anterior mediastinum group, 32 had MG.

\section{Middle Mediastinal Mass Group}

Of the 40 patients in the middle mediastinum group, 12 were female and 28 were male. The mean age of the patients was 34.2 years. In this group, 19 patients were asymptomatic and chest pain (5) was the most common complaint. The mean hospital stay was 6.1 days. None of the patients in this group had a preoperative diagnosis and no diagnostic procedure was performed. All patients were evaluated with thorax CT scan. While 29 of the lesions were approached with thoracotomy, 5 had VATS and 2 had median sternotomy. The most common pathological result was pericardial cyst in 18 (45\%) patients.

\section{Posterior Mediastinal Mass Group}

Of the 37 patients in the posterior mediastinum group, 31 were male and 6 were female. The mean age of the patients in 


\begin{tabular}{|c|c|c|c|c|c|}
\hline Group & Pathology & $\mathbf{n}$ & Group & Pathology & $\mathbf{n}$ \\
\hline \multirow{10}{*}{ Thymic Lesions } & Thymoma & 36 & & Germ cell tumor & 9 \\
\hline & Thymic hyperplasia & 31 & & Teratoma & 5 \\
\hline & Thymic cyst & 8 & & Teratocarcinoma & 1 \\
\hline & Thymic carcinoid & 1 & Other & Solitary fibrous tumor & 1 \\
\hline & Thymic carcinoma & 4 & & Sclerosing periaortitis & 1 \\
\hline & Thymohemangiolipoma & 2 & & Castleman disease & 2 \\
\hline & Metastasis of squamous cell carcinoma & 2 & & Hydatid cyst & 1 \\
\hline & Thymolipoma & 7 & & Schwannoma & 12 \\
\hline & Thymic B-cell Lymphoma & 1 & & Ganglioneuroma & 3 \\
\hline & $\begin{array}{l}\text { Thymic large cell neuroendocrine carci- } \\
\text { noma }\end{array}$ & 1 & & Paraganglioma & 1 \\
\hline \multicolumn{2}{|l|}{ Normal Thymus } & 7 & & Lymphangioma & 1 \\
\hline \multirow{4}{*}{ Thyroid Lesions } & Thyroid nodule & 1 & & Leiomyoma & 2 \\
\hline & Thyroid papillary carcinoma & 3 & & Calcified fibrous tumor & 1 \\
\hline & Nodular goiter & 7 & & Angiosarcoma & 1 \\
\hline & Parathyroid adenoma & 5 & & Head and neck tumor & 1 \\
\hline \multicolumn{2}{|l|}{ Lymphoma } & 21 & & Langerhans cell histiocytosis & 1 \\
\hline \multirow{6}{*}{ Cystic Lesions } & Pericardial cyst & 19 & & Hemangiopericytoma & 1 \\
\hline & Bronchogenic cyst & 16 & & Dendritic reticulum cell tumor & 2 \\
\hline & Esophageal duplication cyst & 2 & & Lymph node & 2 \\
\hline & Gastroenteric cyst & 1 & Unknown & & 8 \\
\hline & Simple cyst & 7 & Insufficient material & & 2 \\
\hline & Paraesophageal cyst & 1 & & & \\
\hline \multicolumn{5}{|l|}{ Total } & 241 \\
\hline
\end{tabular}

this group was 28.1 years. Twenty-one (56.8\%) patients were asymptomatic. Among the symptomatic patients, the most common complaint was chest pain. Two patients in this patient group were evaluated with thoracic MRI, while 1 patient had additional PET-CT scan. The remaining 35 (94.6\%) patients were evaluated with thorax CT scan. None of the 37 patients underwent invasive procedures for preoperative diagnosis. Twenty-five of these lesions were treated by thoracotomy, 6 by robotic surgery and 6 by VATS. The most common pathology in this group was schwannoma in $12(32.4 \%)$ patients. The histopathological distribution of the all operated primary mediastinal lesions and their locations were summarized in Table-3.

A total of 65 median sternotomies were performed for all of the patients and 63 of them were performed for anterior mediastinal lesions. One patient, who was approached with median sternotomy in the middle mediastinal group, was brought into the emergency room of our hospital with respiratory arrest and emergency sternotomy was performed for urgent decompression to trachea. The past medical records of patient were unknown. The postoperative pathology of this patient was reported as lymphoma. The patient has been followed-up for eight years following postoperative chemotherapy. One patient underwent sternotomy for paraaortic mass excision. According to the postoperative pathology report, sclerosing periaortitis was found.
A total of 69 patients underwent robotic surgery and 59 $(85.5 \%)$ of them were performed for anterior mediastinal lesions.

In our study, there were 33 patients diagnosed with MG. There were 11 male and 22 female patients with a mean age of 36.7 years. The most common complaint in these patients was ptosis and weakness. The lesions of all patients were located in the anterior mediastinum. Twenty-two of these patients were treated with robotic surgery, 10 were treated with sternotomy and one patient was treated with VATS. Postoperative pathologic evaluation revealed thymic hyperplasia in 15 patients, thymoma in 8 patients, thymolipoma in 5 patients and normal thymus tissue in 3 patients (Table-4). The mean length of hospital stay in MG patients was 3.7 days. The mean length of hospi-

Table-4: Pathology results of patients operated only with the diagnosis of Myasthenia Gravis.

\begin{tabular}{lc|}
\hline Patology & Total \\
\hline Thymic hyperplasia & 16 \\
\hline Thymoma & 9 \\
\hline Thymolipoma & 5 \\
\hline Normal thymus tissue & 3 \\
\hline Total & $\mathbf{3 3}$ \\
\hline
\end{tabular}


talization of MG patients who underwent sternotomy procedure was 5.7 days while the number of patients who underwent robotic surgery was 2.8 days.

\section{Discussion}

Management of a mediastinal mass is challenging due to a wide range of disease process ranging from benign thymic cyst to lymphoma, or metastatic malignancies from other primaries and limited anatomic work space (5). Benign lesions of the mediastinum are more common than malignant. The rate of malignant lesions in the literature ranges between $24-42 \%$ (6). In accordance with the literature, total benign lesions in our study were more than malign lesions. Of the cases, $169(70.1 \%)$ were benign and $72(29.9 \%)$ were malignant. Mediastinal lesions can be seen at any age. The mean age of the patients was 35.8 years in our study. The anterior mediastinum is the most common site of mediastinal masses (6). In accordance with the literature, in our study, the majority of cases $(68 \%)$ were located in the anterior mediastinum.

The symptoms vary according to the location of the lesions. In our series, 84 (34.9\%) patients were asymptomatic. Most asymptomatic patients (52.4\%) were located in the anterior mediastinum. Although asymptomatic cases are likely to be benign lesions, mediastinal masses detected in the asymptomatic period should never be interpreted as benign unless histopathological diagnosis is made (7). Similar to the literature (8), dyspnea and chest pain were the most common symptoms among patients. In addition, the most symptomatic patient group were patients with lymphoma and preoperative MG patients. It has been reported in the literature that the potential for malignancy with symptoms are directly proportional (7). Our study also confirmed this result.

A total of $237(98.3 \%)$ patients were evaluated with thorax CT. CT and MRI tests are used to determine the invasive potential of the mass, its relationship to the surrounding tissues and its invasive potential. The authors stated that the MRI tests have superiority to determine the local invasion of the lesions (9). MRI has advantage to show the relations with vascular structures and neurogenic tumors located in the posterior mediastinum (10). Also, in some cases scintigraphy will be helpful.

Pericardial and bronchogenic cysts have been reported to be the most common mediastinal cysts (11). The most common cysts in our series were also bronchogenic and pericardial cysts.

Often, preoperative diagnostic procedures cannot be performed according to the location of the lesion. In our series, 35 patients underwent CT-guided transthoracic needle biopsy for preoperative diagnosis but only 20 patients were diagnosed, and all lesions were located in the anterior mediastinum. These unsuccessful biopsy attempts (about $43 \%$ unsuccessful biopsies) are not limited only with our study, it is also stated in Yim's article (12). In addition, 17 patients with anterior mediastinal lesion were diagnosed with anterior mediastinotomy. Especially in the middle mediastinal masses, since the diagnostic procedure is not suitable for the application, no diagnostic procedure can be performed in the preoperative period.

It is decided according to the localization and the nature of the lesion while performing surgical intervention on the mediastinal lesions. There are different surgical approaches to mediastinal masses such as median sternotomy, thoracotomy, VATS, anterior mediastinotomy and robotic surgical approach- es. In the 16-year period in our study, most of the initial surgical procedures were performed by median sternotomy and thoracotomy, whereas VATS and robotic surgery were the most common surgical procedures for the last 5 years. In our case series, robotic surgery was mostly applied for anterior mediastinal masses $(n=59,85.5 \%)$. Before the use of robotic surgery in our clinic, the most performed surgery for anterior mediastinal masses was sternotomy which had many undesirable effects such as more pain, more hospital stay, longer recovery time, sternal infection or dehiscence. Weksler et al. in their study revealed decreased post-operative complications, decreased length of stay, and better outcome of RATS in comparison with open mediastinal tumor resection (13). In our study, when comparing the hospital stay for all patients after major surgical procedure, the longest hospital stay was 7.6 days by thoracotomy, followed by sternotomy with 6.5 days and the shortest duration of stay was 2.8 days with robotic surgery (Table-5).

\begin{tabular}{lc}
\hline $\begin{array}{l}\text { Table-5: Mean length of hospital stay according to major } \\
\text { surgical procedures }\end{array}$ & Mean hospital Stay (Days) \\
\hline Surgical Technique & 7.6 \\
\hline Thoracotomy & 6.5 \\
\hline Sternotomy & 4.4 \\
\hline VATS & 2.8 \\
\hline RATS
\end{tabular}

\section{Conclusion}

Preoperative evaluation of mediastinal lesions should be performed carefully. The appropriate surgical procedure should be selected according to the location of the lesion, depth of invasion of the tumor, and complete resection should always be targeted. The advantages of minimally invasive procedures should always be considered for selected tumors and selected patients. Minimally invasive procedures such as VATS and RATS can be used safely in the complete resection of selected mediastinal masses, which have been accepted in many major centers in the world, and also in our clinic, as in the last 5 years.

\section{Acknowledgments}

Authorship contributions: Concept: E.S.; Design: E.S., M.Ş.I., H.I.; Supervision: K.K., O.G.; Resources: E.S., H.I., O.G.; Materials: H.I., K.K.; Data collection and/or processing: E.S., M.Ş.I.,, H.I., O.K.; Analysis and/or interpretation: E.S., M.Ş.I.., H.I., O.K., K.K.; Writing: M.Ş.I., E.S., K.K.; Critical review: O.G.

Conflict of Interest: The authors declared they do not have anything to disclose regarding conflict of interest with respect to this manuscript.

\section{References}

1. Gun F, Erginel B, Nvar A. Mediastinal masses in children: Experience with 120 cases. Pediatr Hematol Oncol. 2012;29(2):141-147.

2. D'Andrilli A, Venuta F, Rendina EA. Surgical Approaches for Invasive Tumors of the Anterior Mediastinum. Thorac Surg Clin. 2010;20(2):265-284.

3. Kavakli K, Gürkök S, Sapmaz E, Karatas O, Gözübüyük A. Robotic approach to benign mediastinal lesions. Turkish J Thorac Cardiovasc Surg. 2016;24(2):319-324. 
4. Jurado J, Javidfar J, Newmark A, et al. Minimally invasive thymectomy and open thymectomy: Outcome analysis of 263 patients. Ann Thorac Surg. 2012;94(3):974-982.'

5. Radkani P, Joshi D, Barot T, Williams R. Robotic video-assisted thoracoscopy: minimally invasive approach for management of mediastinal tumors. J Robot Surg. 2018;12(1):75-79.

6. Sarper A, Gürkök S, Özuslu BA, Genç O, Balkanlı K. Primer mediastinal kitleler: 64 olgunun analizi. Türk Göğüs Kalp Damar Cerrahisi Derg. 2001;9(3):153-155.

7. Akal M, Özdemir N, Ökten I YS. Mediastinal Kitleler (344 Olguluk Serinin Retrospektif Analizi). Ankara Üniversitesi Tıp Fakültesi Mecmuası. 1995;48(2):233-242.

8. Ayan E, Duran M. Mediastinal Kitleler : 27 Olgunun Değerlendirilmesi Özet. 2005;13(2):127-130.

9. Özgökçe M, Alper F, Aydin Y, Oğul H, Akgün M. Using cine magnetic resonance imaging to evaluate the degree of invasion in mediastinal masses. Turkish $\mathrm{J}$ Thorac Cardiovasc Surg. 2015;23(2):309-315.

10. Yıldız D, Türüt $H$, Sırmalı $M$, et al. Mediastinal kitlelerde cerrahi yaklaşım: 142 olgunun değerlendirilmesi. SDÜ Tıp Fakültesi Derg. 2009;12(1):5-9.

11. Sarkaria IS, Bains MS, Sood S, et al. Resection of primary mediastinal non-seminomatous germ cell tumors: A 28-year experi- ence at memorial sloan-kettering cancer center. J Tho- rac Oncol. 2011;6(7):1236-1241.

12. Yim APC. Video-assisted thoracoscopic management of anterior mediastinal masses. Surg Endosc. 1995;9:1184-1188.

13. Weksler B, Tavares J, Newhook TE, Greenleaf CE, Diehl JT. Robot-assisted thymectomy is superior to transsternal thymectomy. Surg Endosc. 2012;26(1):261-216. 